\title{
Retomando a medição no ensino médio: uma experiência didática
}

\author{
César Augusto Steffens* \\ Eliane Angela Veit** \\ Fernando Lang da Silveira***
}

Resumo: Apresentamos neste trabalho uma experiência em sala de aula realizada no Colégio de Aplicação da UFRGS, na disciplina de Enriquecimento Curricular intitulada "Que medida é esta?", na qual os alunos desenvolveram atividades, experimentais e de outros tipos, envolvendo a medição como um processo de aquisição de dados. Foram elaborados guias de atividades, com tarefas e desafios, que orientaram o trabalho dos alunos, primeiro em pequenos grupos (dois ou três alunos por grupo), nos quais realizaram medições, análise de dados qualitativos e quantitativos, responderam a questóes específicas e a questionamentos sobre os dados e resultados por eles obtidos. As descobertas, os conceitos trabalhados e os resultados obtidos eram sempre confrontados e socializados ao final do encontro, envolvendo os alunos em discussóes, complementadas ou não pelo professor. $\mathrm{O}$ aumento do interesse e participação dos alunos na execução das tarefas e questionamentos propostos, na prontidão e pré-disposição positiva para iniciar novas atividades, sem contar a qualidade dos registros, a satisfação na realização das atividades e na socialização dos resultados validaram o trabalho desenvolvido e os objetivos gerais e aspirações por nós vislumbrados no planejamento inicial.

* Mestre em Física pela UFRGS. Professor de Física da UFRGS. E-mail: cesar@cap. ufrgs.br

** Mestre em Física pela UFRGS, doutora em Ciências pela UFRGS. Professor-associado da Universidade Federal do Rio Grande do Sul. Pós-Doutorado pela University of British Columbia. Bolsista do Conselho Nacional de Desenvolvimento Científico e Tecnológico, CNPq, Brasil. E-mail: eav@if.ufrgs.br

*** Mestre em Física pela UFRGS, doutor em Educação pela PUCRS. Professor associado da Universidade Federal do Rio Grande do Sul. Docente do Programa de PósGraduação em Ensino de Física do IF-UFRGS. URL da Homepage: http://www. if.ufrgs.br/ lang/E-mail: lang@if.ufrgs.br 
Palavras-chave: Física, Ensino Médio, Medição, Aquisição de dados.

\begin{abstract}
In this work is presented a classroom experience realized at "Colégio de Aplicação da UFRGS" (Public Rio Grande Do Sul Federal High School), at the curricular enrichment discipline entitle "What measure is this?", in which the students developed experimental activities involving the measurement as an acquisition process of data. Were elaborated activities guides, based on challenges, guiding the students tasks, first in reduced groups (two or three students by group), collecting measurements, qualitative and quantitative data analysis, answering specific questions and questions about the collected information. The discoveries and concepts were always discussed and worked in the end of the meeting, involving the students in the discussion, supplemented or not by the teacher. The increased interest and participation of the students about the tasks execution and question proposed, in the readiness and positive pre-disposition to start new activities, in addition to the quality of the records, the satisfaction in the activities achieved and socializing resolutions validated the work and the general goals and aspirations projected in the planned activities.
\end{abstract}

Keywords: Physics, High School, Measurement, Data acquisition.

\title{
Introdução
}

Em consonância com os Parâmetros Curriculares Nacionais das Ciências Naturais (BRASIL, 1999) é desejável que os alunos vivenciem conceitos, definições e aplicações em laboratórios didáticos, utilizando instrumentos específicos, unidades e processos adequados às medições realizadas. Para tanto é necessária uma abordagem adequada às estimativas, aos erros e aos desvios ocorridos no processo, como 
também o estudo das principais relações que podem ser estabelecidas entre as grandezas selecionadas para estudo. Acrescente-se a isto, o uso de tecnologias de informação e de comunicação, como o uso do microcomputador e de instrumental científico existente no mercado.

As atividades de laboratório são raras na maioria das escolas e quando acontecem costumam ser conduzidas com roteiros rigidamente estruturados tipo "receita de bolo", o que não tem contribuído efetivamente para propiciar condições favoráveis ao desenvolvimento das habilidades e competências requeridas em um ambiente em que se desenvolvem atividades de Física experimental.

O trabalho aqui relatado foi desenvolvido com a intenção de se dispor de uma proposta complementar para a sala de aula tradicional, em que constem tarefas e desafios experimentais e de outros tipos, num laboratório didático de Física, com materiais de fácil aquisição, com recursos de multimídia e guias de atividades, propiciando aos alunos uma real oportunidade de suprir parte das lacunas de conhecimentos e habilidades requeridas para a execução de experimentos didáticos de Física no Ensino Médio mais elaborados.

O material instrucional impresso (guias), com tarefas e desafios, orienta inicialmente o trabalho dos alunos em pequenos grupos (dois ou três alunos/grupo). A ideia é propiciar a oportunidade de construção do conhecimento sobre a medição de grandezas em Física, através da testagem e exploração de materiais fornecidos aos alunos, sempre socializando as suas descobertas e conclusões nos pequenos grupos e complementando com discussões entre todos os alunos, envolvendo ou não o professor.

Neste trabalho apresentaremos, primeiro, sucintamente o conjunto de atividades desenvolvidas e, à guisa de exemplificação, descrevemos apenas duas delas. As atividades realizadas se centraram no processo da medição, envolvendo medidas manuais, exercícios sobre ordens de grandeza, utilização de notação científica, algarismos significativos e erros. Foram utilizadas também simulações, vídeos, manuseio de sensores, com uma introdução ao estudo de circuitos elétricos e à aquisição automática de dados, bem como a investigação das relações entre grandezas físicas 
observadas em um mesmo fenômeno físico e noções sobre o ajuste de funções a dados experimentais.

\section{Atividades realizadas}

As atividades propostas foram desenvolvidas na escola pública de Ensino Fundamental e Médio "Colégio de Aplicação da UFRGS", em situaçốes de sala de aula para dois grupos de alunos de segundo ano do Ensino Médio, em uma disciplina eletiva do Enriquecimento Curricular intitulada "Que medida é esta?”. A primeira versão (primeiro grupo) aconteceu no segundo semestre de 2007 e a versão final (segundo grupo) foi efetivada no primeiro semestre de 2008, tendo algumas modificações em relação à primeira versão.

A disciplina de Enriquecimento Curricular é eletiva, constando do currículo dos primeiros e segundos anos do Ensino Médio do Colégio de Aplicação. Esta disciplina é semestral, com duas horas/aula semanais, contando com dez a quinze modalidades diferenciadas oferecidas e apresentadas formalmente aos alunos destas séries, por professores das diversas áreas, visando diversificar e aprimorar a formação dos alunos nas áreas que lhes interessam ou estejam relacionadas com a sua formação profissional. Logo, os alunos desta escola elegem e participam de quatro disciplinas de Enriquecimento Curricular durante o seu Ensino Médio.

Na disciplina “Que medida é esta?” são abordados assuntos diversos de Física, como a Mecânica, a Ondulatória e o Eletromagnetismo, além do uso de tecnologias de informação e comunicação, especificamente o microcomputador como instrumento de medida, de simulação e de manipulação de dados. As atividades desenvolvidas nesta disciplina são inicialmente simples e com um aprofundamento progressivo em cada etapa, favorecendo e promovendo a interação dos alunos entre si e com o material instrucional, mediadas pelo professor. $\mathrm{O}$ embasamento teórico 
para estas atividades está apoiado na teoria construtiva sociointeracionista de Vygotsky, na qual o desenvolvimento cognitivo de um indivíduo necessita ter como referência o seu contexto social, histórico e cultural, seus signos e instrumentos, tendo a sua origem nos processos sociais. Os parceiros menos capazes se apropriam da linguagem e do pensamento dos mais capazes, através da interação socioverbal, adquirindo e construindo seus novos conhecimentos (VYGOTSKY, 2003).

Uma boa parte das atividades realizadas é composta de experimentos, reais ou virtuais, que procuram apresentar um questionamento interessante e instigante a ser resolvido pelos alunos. Elas foram elaboradas visando um trabalho em duas etapas, primeiro, em pequenos grupos (dois ou três alunos), executando tarefas de medições, análise de dados qualitativos e quantitativos, resolução de questões específicas e resposta a questionamentos sobre os dados e resultados por eles obtidos. Nessa etapa o professor atuou como um mediador na interação construtiva entre os alunos de cada um dos grupos e entre eles e os materiais produzidos (VYGOTSKY, 2003).

Ao completarem as tarefas propostas para os pequenos grupos, os resultados e as descobertas ocorridas durante o processo de investigação/simulação eram compartilhados com o grande grupo e enriquecidos pelas críticas e soluções individuais encontradas na etapa anterior. No encontro seguinte, antes do início da nova atividade, o professor retomava as conclusões e descobertas mais importantes ocorridas na atividade da semana anterior, registrando algumas no quadro-verde.

A Tabela 1 apresenta uma síntese das atividades, contendo a ordem de sua aplicação, a problemática apresentada e os assuntos envolvidos na sua execução. 


\begin{tabular}{|c|c|c|}
\hline Ordem & Problemática da atividade & Assuntos envolvidos \\
\hline $1^{\mathrm{a}}$ & $\begin{array}{l}\text { Para que medir? É possível } \\
\text { confiar }\end{array}$ & $\begin{array}{c}\text { Grandezas físicas, Estimativas, Medições, Instru- } \\
\text { mentos de Medida, Padrão de Medida, Unidade de } \\
\text { Medida, Erros e Diferenças Absolutas e Relativas. } \\
\text { (Medidas diretas) }\end{array}$ \\
\hline $2^{\mathrm{a}}$ & $\begin{array}{l}\text { O que é grande? O que é } \\
\text { pequeno? }\end{array}$ & $\begin{array}{c}\text { Medidas Macroscópicas e Microscópicas de } \\
\text { Comprimento, Notação Científica, Ordem de } \\
\text { Grandeza, Mapas, Escalas, Regra de Três Simples, } \\
\text { Prefixos Gregos e Latinos. }\end{array}$ \\
\hline $3^{\mathrm{a}}$ & $\begin{array}{l}\text { Tu percebes o que acontece ao } \\
\text { teu redor? Mesmo estando } \\
\text { "ligadão"? }\end{array}$ & $\begin{array}{l}\text { Estimativas, Medidas de Intervalo de Tempo, } \\
\text { Diferença Absoluta e Percentual. } \\
\text { (Análise de Vídeos Youtube com Eventos) } \\
\text { (Medidas diretas e indiretas) }\end{array}$ \\
\hline $4^{\mathrm{a}}$ & $\begin{array}{c}\text { Como tu determinarias esta } \\
\text { grandeza física? }\end{array}$ & $\begin{array}{c}\text { Medidas de Massa, Área e Volume de Objetos. } \\
\text { Contagens e Medidas Diretas e Indiretas. } \\
\text { Estatísticas e Previsões. }\end{array}$ \\
\hline $5^{\mathrm{a}}$ & $\begin{array}{l}\text { Quais as medidas biológicas } \\
\text { Mais comuns do teu corpo? }\end{array}$ & $\begin{array}{l}\text { Medidas Clínicas: Pressão, volume e temperatura. } \\
\text { Temperatura corpórea, Pressão Arterial, Pressão } \\
\text { Pulmonar Máxima de Expiração, Volume Pulmo- } \\
\text { nar Máximo de Aspiração. }\end{array}$ \\
\hline $6^{\mathrm{a}}$ & $\begin{array}{l}\text { Com quantos decimais } \\
\text { devemos expressar uma } \\
\text { medida? }\end{array}$ & $\begin{array}{l}\text { Tempo de Reação, Instrumentos e Precisão. } \\
\text { Algarismos Significativos e Algarismo Duvidoso. } \\
\text { Confiabilidade. }\end{array}$ \\
\hline $7^{\mathrm{a}}$ & $\begin{array}{c}\text { Como funcionam os sensores } \\
\text { elétricos? }\end{array}$ & $\begin{array}{l}\text { Circuito Elétrico: Gerador, Conector, Condutor, } \\
\text { Interruptor, Resistor, Resistor Variável, Lâmpada } \\
\text { Incandescente, Led e Multímetro (V, A, } \Omega \text { ). } \\
\text { Relação: Resistência Elétrica x Desvio Angular. }\end{array}$ \\
\hline $8^{\mathrm{a}}$ & $\begin{array}{l}\text { Para que servem e como } \\
\text { funcionam os transdutores? }\end{array}$ & $\begin{array}{l}\text { Características físicas, de excitação e resistivas de } \\
\text { um transdutor (sensor) comum. } \\
\text { Programa Aqdados (p/Leitura de dados), Placa de } \\
\text { Som e Resistor Variável (Desvio Angular) }\end{array}$ \\
\hline $9^{\mathrm{a}}$ & $\begin{array}{c}\text { Como fazer o microcomputador } \\
\text { ler os dados } \\
\text { fornecidos pelos transdutores? }\end{array}$ & $\begin{array}{l}\text { Transdutores em geral: características elétricas. } \\
\text { Programa Aqdados: Leitura Analógica e Digital. }\end{array}$ \\
\hline $10^{\mathrm{a}}$ & $\begin{array}{c}\text { Como importar os dados } \\
\text { obtidos automaticamente com } \\
\text { o programa Aqdados? }\end{array}$ & $\begin{array}{l}\text { Programa Aqdados e Planilha Excel (p/Captura). } \\
\text { Medidas do Período e Velocidade num Pêndulo. } \\
\text { Relação: Amplitude x Resistência Elétrica. }\end{array}$ \\
\hline
\end{tabular}




\begin{tabular}{|c|c|c|}
\hline $11^{\mathrm{a}}$ & $\begin{array}{c}\text { Como medir a velocidade do } \\
\text { som na sala de aula? }\end{array}$ & $\begin{array}{c}\text { Microfone a Eletreto e "Amplificação". } \\
\text { Som estéreo (dois canais). } \\
\text { Programa Goldwave (p/Análise de Som). }\end{array}$ \\
\hline $12^{\mathrm{a}}$ & $\begin{array}{c}\text { Quais as principais relações } \\
\text { que podem ser estabelecidas } \\
\text { entre grandezas Físicas de } \\
\text { um mesmo fenômeno? (I) }\end{array}$ & $\begin{array}{c}\text { Grandezas Físicas Diretamente Proporcionais. } \\
\text { Tabelas, Equaçốes e Gráficos. Propriedades, e } \\
\text { outras relaçóes. }\end{array}$ \\
\hline $13^{\mathrm{a}}$ & $\begin{array}{c}\text { Quais as principais relaçốes } \\
\text { que podem ser estabelecidas } \\
\text { entre grandezas Físicas de } \\
\text { um mesmo fenômeno? (II) }\end{array}$ & $\begin{array}{c}\text { Grandezas Físicas Inversamente Proporcionais. } \\
\text { Tabelas, Equações e Gráficos. Propriedades. }\end{array}$ \\
\hline
\end{tabular}

Tabela 1: Atividade proposta, com o código de identificação do correspondente guia de atividade elaborado para os alunos e os assuntos envolvidos em sua execução.

\section{Alguns exemplos das atividades realizadas}

Para ilustrar as atividades realizadas, escolhemos duas que nos parecem ser especialmente significativas, pelo trabalho realizado, pelo envolvimento e satisfação apresentado pelas maioria dos alunos, tanto oralmente em conversas informais com o professor no desenvolvimento delas, como nos questionamentos realizados no final de cada semestre.

\section{Atividade $N^{\circ}$. 2: O que é grande? O que é pequeno?}

Tanto a compreensão do significado de medidas muito pequenas e/ou muito grandes, utilizando a notação científica ou suas ordens de grandeza, quanto a determinação de distâncias reais (comprimentos) em mapas ou fotografias com escalas definidas, constituem-se em notórias dificuldades para os alunos. A proposição de uma atividade, em duas etapas, como o intuito de promover a superação de parte destas dificuldades, envolveu 
dois sites com softwares disponíveis na Internet.

A primeira etapa utiliza um site que apresenta as fotos, medidas arbitrárias e ordens de grandeza de objetos, indo do quark ao universo conhecido, pois acreditamos que a associação visual dos objetos com as suas reais medidas favorece o uso de ordem de grandeza e notação científica. A segunda etapa utiliza um site que apresenta mapas e fotos de satélite com escalas apropriadas, permitindo a medida de comprimentos como o diâmetro da Terra até detalhes menores do que $10 \mathrm{~m}$ em sua superfície, como a largura de um dos prédios do Colégio de Aplicação da UFRGS.

Iniciando a primeira etapa desta atividade virtual, os alunos acionaram o Navegador da Internet e a página de Molecular Expressions (MOLECULAR EXPRESSIONS ${ }^{\mathrm{TM}}$, 2008), onde existe um simulador que apresenta sequencialmente as imagens de diversos "corpos" celestes e seus diâmetros, com sua medida expressa literalmente, numa unidade apropriada, e sua ordem de grandeza, partindo do diâmetro de um quark $\left(\sim 10^{-16} \mathrm{~m}\right)$ até a

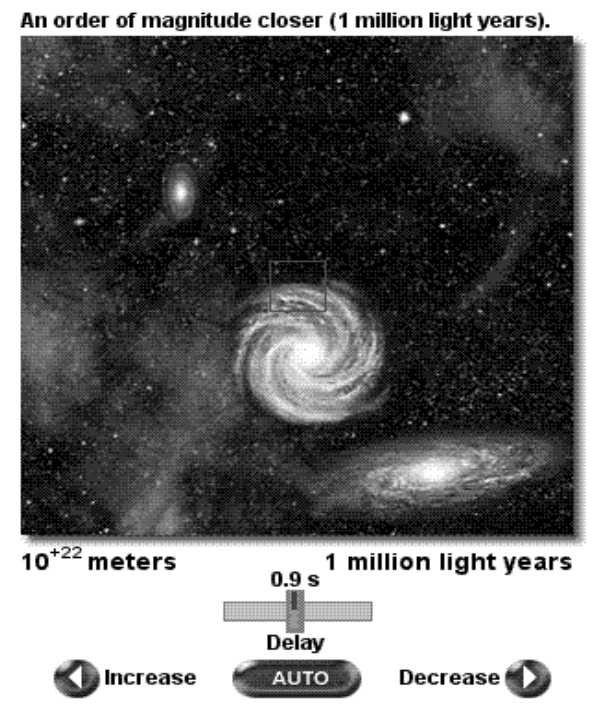

extensão do universo conhecido $\left(\sim 10^{23} \mathrm{~m}\right)$.

Fig. 1: Simulador da página do Molecular Expressions. 
Neste site os alunos observaram, com muita atenção e interesse, os diversos “corpos celestes” e suas medidas, registrando numa tabela apropriada, primeiro as ordens de grandezas das medidas destes corpos e depois as reescreveram na forma decimal (literalmente descritas). Como exercício de reforço imediato, a partir de outras medidas apresentadas sob a forma de notação científica, os alunos determinaram e registraram as ordens de grandeza e as medidas decimais correspondentes às apresentadas, sendo ajudados por colegas e pelo professor a resolver suas dúvidas e dificuldades. A cooperação dos colegas mais aptos foi muito significativa e permitiu a todos a completar a tarefa com segurança. A pedido dos alunos foi retomada a unidade de distâncias astronômicas ano-luz, definida como a distância que a luz percorre, em um ano, com a velocidade aproximada de $300.000 .000 \mathrm{~m} / \mathrm{s}$, calculada por dois grupos conforme abaixo:

$$
\begin{gathered}
\mathbf{d}_{(\mathbf{1} \text { ano-luz) }}=\mathbf{v}_{\text {luz. }} \Delta \mathbf{t}_{(1 \text { ano })} \cong 300.000 .000 \mathrm{~m} / \mathrm{s} \times 365 \mathrm{~d} \times 24 \mathrm{~h} / \mathrm{d} \mathrm{x} \\
\quad 60 \mathrm{~min} / \mathrm{h} \mathrm{x} 60 \mathrm{~s} / \mathrm{min} \\
\mathbf{d}_{(\mathbf{1} \text { ano-luz) }} \cong 9.460 .800 .000 .000 .000 \mathrm{~m} \cong 9,5 \times 10^{15} \mathrm{~m}
\end{gathered}
$$

Na segunda etapa, os grupos acionaram a página do Google Maps (GOOGLE, 2008), envolvendo a localização da UFRGS e do Colégio de Aplicação em Porto Alegre (Campus do Vale), através de fotos de satélite da superfície da Terra, com detalhes que chegam até a extensão de 1,0m. Após a seleção dos objetos indicados, os alunos realizaram as medições dos comprimentos e larguras destes, através do uso tanto das escalas existentes nas fotos aéreas dos locais como de pequenas réguas, diretamente colocadas sobre a tela do microcomputador, obtidas indiretamente através de convenientes regras de três. Foi possível avaliar o resultado de algumas destas medidas indiretas, medindo diretamente o tamanho real da largura do prédio onde estavam.

No final da atividade, algumas medidas obtidas nos grupos foram comparadas, confirmando a maioria dos valores encontrados, em pouquíssimos casos corrigindo e acertando as medidas pouco divergentes, além de registrarem as dificuldades mais comuns 
encontradas na determinação das medições solicitadas, como o uso de notação científica, a utilização das escalas nos mapas, fotos e a famosa "regra de três". A Figura 2 apresenta a foto do prédio do Colégio de Aplicação, no Google Maps, vista de um satélite artificial terrestre, com a medida da largura do prédio A deste.

No encontro seguinte foram retomadas algumas medidas, como a largura do prédio A da escola, medida indiretamente por um dos grupos como igual a 20m. Este grupo solicitou ao professor uma trena de $10 \mathrm{~m}$ e foi realizar diretamente a medida, encontrando 20,6m, o que muito os alegrou e serviu de confirmação de domínio do processo.

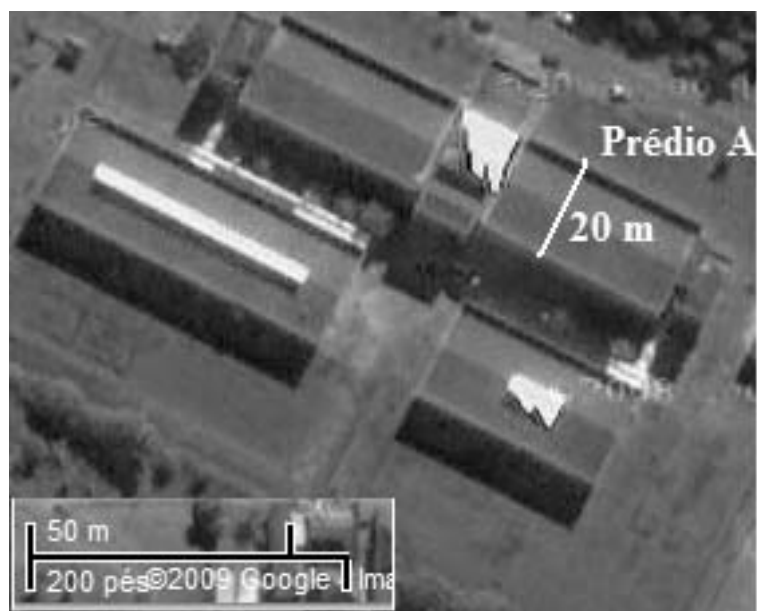

Fig. 2: Foto do Colégio de Aplicação, vista superior, no Google Maps (com a escala).

3.2. Atividade $n^{\circ}$. 11: Como medir a velocidade do som na sala de aula?

Esta atividade foi baseada no trabalho realizado por Grala e Oliveira (2005), onde descrevem a possibilidade de medida da velocidade de propagação do som no ar em um laboratório 
didático de Física de Ensino Médio, utilizando dois microfones a eletreto conectados à "Entrada" (line-in) da placa de som de um microcomputador (para captar uma emissão sonora) e o programa Goldwave v4.26 (para gravações, análise e manipulação de uma emissão sonora)(GOLDWAVE, 2008). Como não existem prontas interfaces potencializadoras entre microfones a eletreto estéreo e a placa de som, montamos e testamos previamente quatro destas interfaces.

No início da atividade, o professor salientou a sua importância, pois a medida da velocidade do som no ar é, via de regra, excluída para alunos de Ensino Médio, pela dificuldade e quase impossibilidade de medição de intervalos de tempo muito pequenos com o instrumental comum existente em laboratórios de Física. Após terem ligado os microcomputadores, cada grupo de alunos recebeu o equipamento com os microfones e o conectou à "Entrada" (line-in) da placa de som de seu microcomputador.

Acionando o programa Goldwave, os alunos foram orientados e desafiados (guia de atividades) a testarem as possibilidades e propriedades do programa, gravando suas vozes e cantorias. Cada um dos grupos teve a oportunidade de trabalhar e brincar com a gravação estéreo do programa Goldwave, inclusive testando outras funções do programa, como reprodução mais lenta ou mais rápida do som gravado e alterações do timbre da voz. Pela primeira vez, segundo eles, produziram uma reprodução com reversão temporal do som gravado, ou seja, rodou a gravação ao contrário, o que atraiu muito a atenção deles, gravando e reproduzindo a famosa canção "Ilarie" (da apresentadora Xuxa) muito conhecida por eles, em mono e estéreo, reproduzindo-a em velocidade normal, em maior e menor velocidade, sem contar com os "efeitos especiais" e ordem inversa, por eles descobertos. Foi um grande momento de produção e descontração, muitos gritos e guinchos, muitas risadas, um real momento de satisfação e felicidade para todos.

A Figura 3 mostra a foto do equipamento utilizado por cada um dos grupos para gravação de sons, com a tela do microcomputador mostrando o teste de gravação estéreo realizado 
por um dos grupos com o programa Goldwave ativo, onde cada um dos alunos cantou num microfone diferente. Após terem se acalmado, iniciaram a atividade propriamente dita, alinhando os dois microfones (vermelho e verde) com a fonte sonora (lata e bastão metálico), como também mostra a Figura 3.

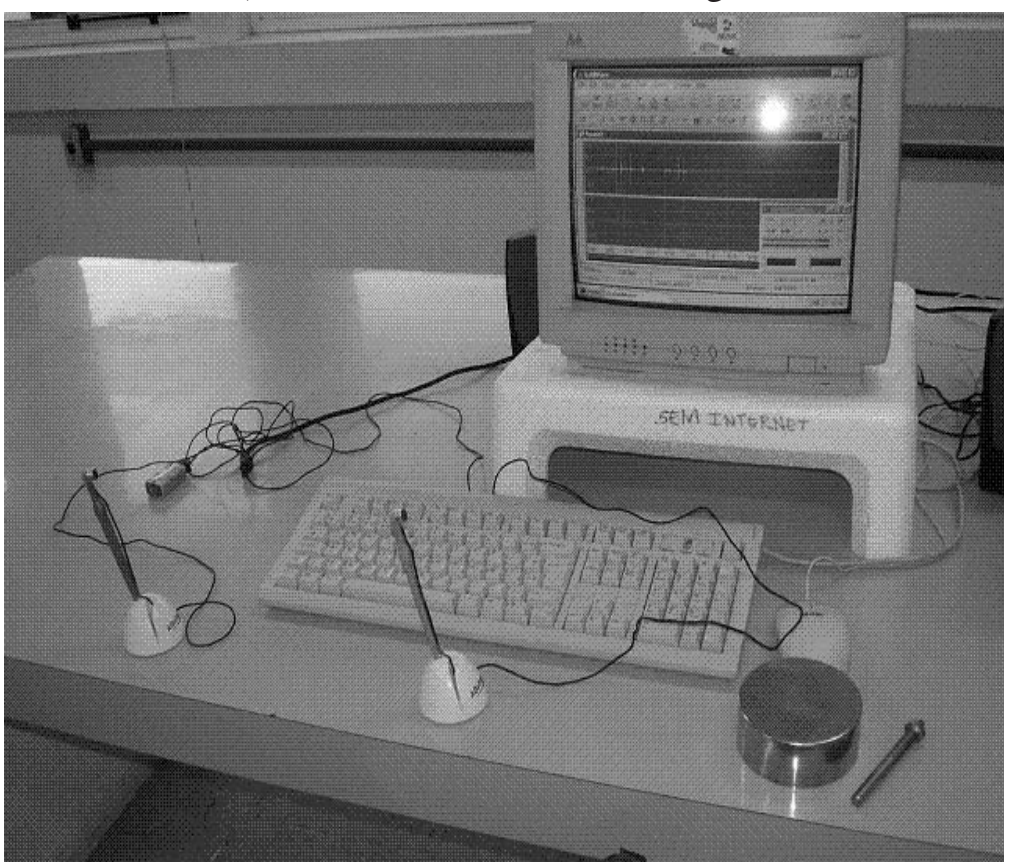

Figura 3: Foto do equipamento utilizado para a gravação estéreo do som.

(STEFFENS, 2008, p. 106, Fig. 46)

Depois, acionaram o programa de gravação e realizaram as cinco batidas na lata, conforme orientava o texto do guia de atividades. Encerrada a gravação, iniciaram a análise do gráfico produzido pelo programa Goldwave, que relaciona a intensidade do som gravado em função do tempo decorrido, onde os alunos facilmente identificaram os inícios dos sons produzidos com as cinco batidas, através dos "picos" de grande amplitude do som gravado. Analisando o gráfico com os registros sonoros das cinco batidas, os alunos selecionaram o primeiro trecho que 
continha o início de recebimento do som, nos dois microfones, da primeira batida. Depois, ampliaram este trecho da trilha sonora três vezes, usando o comando "selecionar" (Sel), até poderem identificar, com grande precisão, os instantes de tempo em que os microfones iniciaram o recebimento do som da primeira batida. Esta ampliação foi acompanhada pelo professor, pois os alunos apresentaram uma relativa dificuldade para selecionar o trecho a ser ampliado e determinar no gráfico o intervalo de tempo envolvido. Sanada a dificuldade, os alunos conseguiram determinar o intervalo de tempo decorrido entre o recebimento deste som pelo primeiro e pelo segundo microfone. A Figura 4 mostra, em detalhes, o mesmo trecho com o registro gráfico de uma batida nos dois microfones (verde e vermelho), em três ampliações consecutivas. No primeiro segmento, a menor divisão do gráfico é de ls, correspondente à imagem na tela; no segundo, é de 0,01 s (centésimos de segundo); no terceiro é de 0,001 s (milésimos de segundo) e no quarto segmento, a menor divisão é de 0,0001s (décimo de milésimos de segundo).

Fig. 4: Gráficos contendo um mesmo trecho com o registro gráfico de uma batida.

(STEFFENS, 2008, p. 108, Fig. 49)
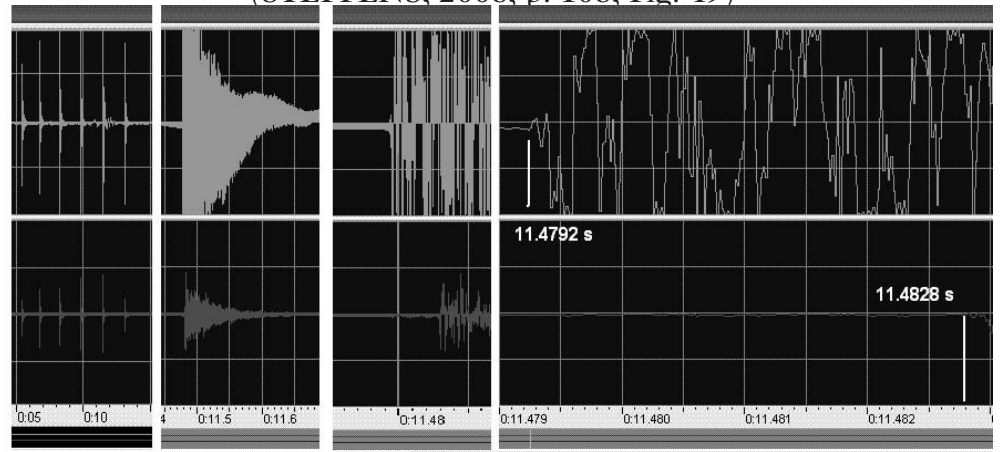

Com domínio do processo, os alunos realizaram sozinhos a medida e o registro dos intervalos de tempo $(\Delta t)$ para as outras batidas. Depois, cada grupo mediu e registrou a distância (d) entre 
os dois microfones, respondendo a quatro questionamentos sobre a atividade até ali desenvolvida.

Com os dados registrados, ou seja, com os intervalos de tempo obtidos e com a distância percorrida pelo som entre os dois microfones (na Figura 5, $\Delta \mathrm{t}=0,0036 \mathrm{~s}$, para $\mathrm{d}=1,22 \mathrm{~m}$ ), os alunos determinaram e registraram a velocidade média de propagação do som para cada uma das batidas, encontrando em torno de $340 \mathrm{~m} / \mathrm{s}$, excelente resultado para uma temperatura de $26^{\circ} \mathrm{C}$.

Para enriquecer ainda a atividade, acessaram uma página da Internet, observando e analisando uma simulação de como ocorre a propagação do som em um meio gasoso. Depois, analisaram dados e informaçôes numéricas contidas em tabelas, responderam à questionamentos desafiadores existentes no guia de atividades, acrescentando informações importantes ao seu conhecimento sobre as ondas sonoras, não vistas em sala de aula, relacionadas a filmes com explosões no espaço e em outras condições de diferente temperaturas e pressão. Muitos alunos não sabiam que o som não se propaga no vácuo e que a velocidade do som é aumentada quando aumenta a agitação térmica das partículas que compõe o ar (aumenta a temperatura).

\section{Dificuldades encontradas}

Ocorreram algumas dificuldades de execução da atividade, entre elas, a lentidão dos computadores (inferiores ao Pentium III), a normal dificuldade de operação de um programa de análise do som como o Goldwave, a imprecisão inicial de leitura e de registros dos intervalos de tempo decorridos entre as recepçóes do som pelos dois microfones, feita em milésimos de segundo, quando necessitava ser de décimos de milésimos de segundo (ou seja 0,0001 s).

Esta atividade também foi aplicada a um grupo de alunos do oitavo semestre da Licenciatura de Física (2008). Embora este grupo tenha sido mais maduro, tranquilo e participativo, com maior habilidade experimental, a determinação dos instantes de 
tempo com cinco a seis algarismos significativos produziu um certo desconforto, pois "nunca haviam procurado tal precisão", diziam eles, sem contar o desconhecimento de algumas propriedades de propagação do som no ar e em outros meios materiais.

Mesmo com as dificuldades encontradas nesta "difícil medição", esta atividade mostrou-se importante, no que tange à aquisição de dados, e significativa para os alunos. Os alunos se motivaram, especialmente, pelo resultado considerado "impossível para eles", porque a atividade foi desenvolvida após um exaustivo trabalho com transdutores e porque na aquisição automática de dados foi usado o programa Aqdados (ARAUJO, 2002), desenvolvido na UFRGS para registrar em uma tabela os dados obtidos com transdutores conectados à placa de som de um microcomputador. Um dos grupos de alunos, na semana seguinte à da atividade realizada com o Goldwave, montou e testou, em horário extraclasse disponibilizado pelo professor, o "potencializador estéreo", para ser utilizado em gravações com instrumentos de cordas, com seu irmão e colegas em sua casa, o que muito nos gratificou.

\section{Considerações finais}

Pelos registros e respostas dadas pelos alunos nos guias de atividades, pelas respostas aos questionários de satisfação e pelos registros feitos pelo professor nas discussôes ao final de cada atividade, envolvendo de 9 a 10 alunos, podemos considerar o trabalho realizado efetivo e contextualizado, contribuindo na busca de novas maneiras de trabalhar a Física no Ensino Médio.

Em geral, os comentários dos alunos quanto ao trabalho desenvolvido e o material utilizado nas atividades foram muito positivos, nos incentivando a uma busca de maior qualidade e atualização em novas propostas de trabalho para o Ensino Médio. Dentre as colocações finais dos alunos, devido ao trabalho diferenciado, mais descontraído e sem pressões diretas de 
avaliação (como provas), destacamos as que deixaram os alunos mais felizes e mais comprometidos com as atividades realizadas. Dos questionários de satisfação aplicados, salientamos os trechos que seguem:

"[...] durante o tempo de aula pude ter bastante interação com meus colegas e professor..."

“...gostei do curso, foi divertido e esclarecedor $[\ldots] "$

"foi excelente as aulas, isso desperta muito mais a vontade do aluno [...]"

Finalmente, como resultados positivos esperados e observados nos alunos podemos citar:

o crescimento da participação nas atividades de laboratório, com muitas discussões e complementações durante e no final de cada atividade, sempre apresentando uma pré-disposição positiva na execução das propostas apresentadas nos guias, mesmo as mais abstratas e formalizadas;

o acerto e o maior cuidado com os registros das respostas às questões formuladas;

a maior satisfação na realização das atividades na busca de soluções alternativas e na socialização de situações vividas individualmente por cada um sobre assuntos pertinentes;

o clima de satisfação entre eles, demonstrado através dos “olhos”, através de seus gestos, através do interesse a detalhes e aceitação da continuidade do trabalho mesmo após o término do período de aula.

Tudo isto gratificou e confirmou a validade do trabalho desenvolvido com os alunos.

Todos os guias de atividades aplicados (STEFFENS, 2008a), os textos de apoio desenvolvidos para os professores (STEFFENS; VEIT; SILVEIRA, 2008) e o relato circunstanciado da utilização destes guias com os alunos de nível médio do Colégio de Aplicação da UFRGS, incluindo as suas respostas às questôes e desafios propostos neles, constam da dissertação de mestrado do primeiro autor desse trabalho (STEFFENS, 2008b), desenvolvida sob orientação dos outros dois autores, junto ao Programa de Pós-Graduação em Ensino de Física da UFRGS. 


\section{Conclusões}

Observamos que esta abordagem diversificada, envolvendo o processo da medição, em diversos ramos da Física, como o uso de tecnologias de informação e comunicação, propicia aos alunos uma real oportunidade de suprir parte das lacunas de conhecimentos e de habilidades ocorridas em sua formação, tanto no Ensino Fundamental como no Médio. Por tudo isso, pretendemos manter esta disciplina no catálogo do Enriquecimento Curricular, e investigar o por que do pequeno número de alunos que optam por disciplinas das exatas como esta, pois observamos que este tipo de proposta também favorece a desmistificação da Física como uma disciplina assustadora, inacessível à media dos alunos.

\section{Referências}

ARAUJO, Ives S. Aqdados. 2002. Disponível em < http://www.if.ufrgs. br/cref/ntef/software/Aqdados20.zip >. Acesso em: 4 de ago. 2009. Software para leitura das entradas da porta de jogos.

BRASIL. Ministério da Educação. Secretaria da Educação Média e Tecnológica. Parâmetros Curriculares Nacionais: ensino médio. Brasília: [MEC], 1999.Disponível em: http://portal.mec.gov.br/seb/arquivos/ pdf/ciencian.pdf. Acesso em 28 de jul. 2009.

GOOGLE. Google Maps. 2008. Disponível em http://maps.google.com/. Acesso em 27 jul. 2009. Serviço on line de localizaçã̃o geográfica mundial.

GOLDWAVE INC. Goldwave 4.2. 2000. Disponível em: http://www. goldwave.com/. Acesso em: 27 mar. 2008. Software de análise de sons.

GRALA, Rita M.; OLIVEIRA, Elisandra. Medida da Velocidade do Som no Ar Com o Uso do Computador. Física na Escola, São Paulo, v 6, n 2, p. 26-28, out. 2005. Disponível em: < http://www.if.ufrgs. br/cref/ntef/som/lab/linein/index.html >. Acesso em: 27 Jul. 2009. 
MOLECULAR EXPRESSIONS ${ }^{\mathrm{TM}}$ Science, Optics and You. 1995. Disponível em http//www.micro.magnet.fsu.edu/primer/java/scienceopticsu/powersofl0/index.html. Acesso em 28 de jul. 2009. Site que apresenta um Java-applet com imagens sequenciais indicando as dimensões e ordens de grandeza de corpos do nosso universo conhecido.

STEFFENS, César A. Caderno de atividades para a introdução da medição num laboratório didático de nível médio / César Augusto Steffens. - Porto Alegre: UFRGS, 2008a. 98p. Disponível em < http://www.if.ufrgs.br/ ppgenfis/index.php > Acesso em 7 ago. 2009.

. Um olhar sobre medidas em física. 2008. 353 fls. Dissertação (Mestrado em Ensino de Física), Instituto de Física, Universidade Federal do Rio Grande do Sul, Porto Alegre, 2008. Disponível em: < http://www.lume.ufrgs.br/handle/10183/14968> Acesso em 28 de jul. 2009.

.; VEIT, Eliane A.; SILVEIRA, Fernando L. Uma Introdução ao Processo da Medição no Ensino Médio - Porto Alegre: UFRGS, Instituto de Física, Programa de Pós-Graduação em Ensino de Física, 2008b. 86p. (Textos de apoio ao professor de Física v 19, n2) Disponível em: http//www.if.ufrgs.br/public/tapf/v19n2_Steffens_Veit_Silveira.pdf. Acesso em 9 de ago. 2009.

VYGOTSKY, Lev S. Pensamento e Linguagem. 3 ed. São Paulo: Martins Fontes, 2003. 135p. 